\title{
EDUCAÇÃO PROFISSIONAL: SEPARAR PARA INCLUIR?
}

\author{
Loni Elisete MANICA ${ }^{1}$ \\ Geraldo CALIMAN $^{2}$
}

RESUMO: No Brasil, as possibilidades e os limites da inclusão de alunos com deficiência $(\mathrm{PcD})$ em classes regulares é um tema que divide opiniões. De um lado, há os que defendem que é possível incluir, todos os estudantes em salas regulares, não importando o tipo de deficiência. De outro, existem aqueles que defendem que, em alguns casos, é melhor para a PcD estudar em uma classe ou escola especial. A reflexão proposta pautará sobre resultados de uma pesquisa inédita de doutorado em educação que trata sobre o tema. Os próprios alunos com deficiência revelam que nem sempre se sentem incluídos em turmas regulares. Qual será a saída?Turmas especiais pode ser uma solução necessária para incluir o excluído?

PALAVRAS-CHAVE: Inclusão. Profissional. Classes especiais.

\section{Introdução}

O passado não pode ser esquecido, a herança das pessoas com deficiência sem formação ou sem escolaridade ainda existe e, não basta entendermos que a inclusão é um direito de todos, sem oferecermos os quesitos necessários ao bom funcionamento de uma escola inclusiva. Defende-se aqui o direito a escolha da pessoa com deficiência. Tal aluno ou aluna com deficiência deve e pode dizer o que ele (a) quer, onde quer estudar, com quem quer estudar, como quer aprender, nem que para isso a escola para ser inclusiva precise separar para posteriormente, incluir. Isso será amplamente discutido no presente texto.

Quando se pensa em conceituar escola inclusiva, logo nos vem à mente aquela que oferece ingresso e acessibilidade a todos os cidadãos. Podem-se descrever inúmeros conceitos que nos levariam a reconhecer a escola inclusiva, mas um conceito geral que tende a reunir todos os princípios pode ser revelado como: escola que está preparada para atuar na diversidade, receber qualquer aluno ou aluna, seja um indivíduo com ou sem deficiência. Sabe-se que essa terminologia 'inclusão' aparece após a Declaração de

\footnotetext{
${ }^{1}$ Doutora em Educação na área da Pedagogia Social. Assessora de Inclusão e Diversidade. Senado Federal. Brasília - DF - Brasil. 70165-900 - loni@ senado.gov.br.

${ }^{2}$ Pós-doutorado e Doutorado em Educação. Università Pontificia Salesiana. Roma - Itália. RM 00139 caliman@ucb.org.br.
} 
Salamanca promulgada em 1999. Atualmente vivemos a era de transição entre a inclusão e a integração ${ }^{3}$.

Inicialmente, para que o leitor entenda melhor os resultados que serão apresentados, se faz necessário explanar quem foram os alunos pesquisados, quais as características, que tipo de deficiência, idade e outros quesitos pessoais dos respondentes da pesquisa, bem como, os objetivos propostos e que subsidiam este texto.

As questões formuladas foram respondidas por trinta e cinco estudantes com deficiência, que participavam da educação profissional de dezoito estados do Brasil. Residentes em Capitais e que na época da geração dos dados, estavam inseridos em algum curso de qualificação na modalidade de aprendizagem industrial.

As questões que aqui serão reveladas e que foram as utilizadas na pesquisa são: que tipo de escola você prefere a inclusiva ou a especial? Se você não sabe ler e escrever como faria para fazer parte de uma classe de alunos no ensino regular? Você considera certo ou errado o fechamento das escolas especiais? Os dezoito estados escolhidos foram aqueles que atuavam com a modalidade de aprendizagem industrial na época da pesquisa.

Um dos dois objetivos traçados na pesquisa e que será tratado neste texto foi investigar analisar e apresentar os limites e as possibilidades da prática inclusiva na educação profissional, com vista a auxiliar as políticas públicas relacionadas à inclusão, bem como a adoção de políticas e práticas viáveis aos ambientes educacionais.

Ressalta-se ainda que nessa pesquisa, os alunos e alunas pesquisados possuem um dos cinco tipos de deficiência mais comum. A pesquisadora entendeu que se deveria antes de apresentar as respostas sobre o tema aqui abordado, registrar um pequeno perfil de quem foram os alunos pesquisados. Desejou-se contemplar os diversos olhares, sob o ponto de vista, de pessoas com deficiência com graus e tipos variados de deficiência e, para isso, procurou-se gerar os dados junto aos vários tipos de alunos que as escolas escolhidas ofereciam, alunos esses que apresentavam características e tipos de deficiência diferenciados, ou seja: trinta e quatro por cento alunos com deficiência auditiva; vinte e nove por cento alunos com deficiência mental e intelectual; vinte e um por cento alunos com deficiência visual; doze por cento foram pesquisados alunos

\footnotetext{
3 Integração: quando a pessoa com deficiência se prepara para ser inserida na sociedade (por si só) independente da acessibilidade oferecida pela sociedade. Inclusão: quando a sociedade como um todo se prepara e se trona totalmente acessível para receber a pessoa com deficiência nos mais diversos ambientes.
} 
deficientes físicos e quatro por cento alunos com deficiência múltipla (que possui dois ou mais tipos de deficiência).

Quanto ao tipo de curso que os respondentes frequentavam na educação profissional, notou-se a variedade de opções, assim: quarenta e três por cento dos pesquisados cursavam auxiliar administrativo; vinte e um por cento curavam logística, onze por cento cursava tecnologia da informação; sete por cento auxiliar de produção e com igual percentual (7\%) o grupo dos pesquisados frequentavam o curso de padeiro, o restante dos alunos pesquisados estavam distribuídos entre as variadas áreas de estudo não citadas.

Quando foram questionados sobre acreditarem ou não no seu potencial, unanimemente a resposta foi positiva. Assim, pensar que as pessoas com deficiência se consideram ineficientes não parece ser verdadeiro. Na visão da pessoa com deficiência $(\mathrm{PcD})$ pesquisada, existe a confiança e a certeza de que se veem com potencial e de que se consideram pessoas aptas para escolher e realizar os cursos de educação profissional. Os alunos com deficiência pesquisados se encontravam na faixa de vinte e um até trinta anos de idade e, aproximadamente, setenta por cento são afrodescendentes.

As respostas aqui evidenciadas não são aquelas desejadas pela pesquisadora ou, muitas vezes idealizadas pelo governo que, muitas vezes, propõe a inclusão como única forma de educar as pessoas com deficiência, nem tão pouco respostas desejadas ou não pela pesquisadora, mas aqui está o registro do público alvo, ou seja, dos alunos(as) com deficiência que estudavam em escolas de educação profissional. São respostas reais de quem pode pensar sugerir e avaliar e, especialmente, respostas polêmicas que vão na contramão do que alguns órgãos governamentais estão propondo e das políticas públicas relacionadas a uma inclusão radical.

Cabe à sociedade ouvi-los, pois se compartilha da ideia de que não podemos tratar de assuntos referentes às pessoas com deficiência, sem consultá-las, ou seja, 'nada sobre nós, sem nós ${ }^{4}$. Se desejarmos uma sociedade liberta de preconceitos, a forma legal não é a imposição, mas a consideração do desejo daquilo que as próprias pessoas com deficiência expressam.

A seguir se revelará alguns conceitos básicos relacionados à escola inclusiva, seus limites e suas possibilidades e, na sequencia, a origem da escola profissional para pessoas com deficiência, temas que serão tratados à luz das respostas compiladas na

\footnotetext{
${ }^{4}$ Lema de 2004 utilizado na divulgação do dia internacional da pessoa com deficiência.
} 
pesquisa. Aparecerão os resultados polêmicos sobre o que pensam os alunos com deficiência na educação profissional, o que é possível, o que é utopia e o que é necessário, se apresentará ainda, o que pensam estes alunos sobre a extinção ou não das escolas especiais.

\section{Escola Inclusiva: Limites e Possibilidades}

Trabalhar em prol de uma escola inclusiva dá a impressão, em alguns momentos, de que se oferece algo que vai além da obrigatoriedade legal, ou parece que se está fazendo caridade. Sabe-se que isso não é verdade, pois apesar da inclusão ser algo recente, historicamente a integração, que antecedeu a fase da inclusão, já estava apoiada em aspectos legais que favoreciam a saída da pessoa com deficiência de seus confinamentos e, além disso, educar com princípios inclusivos é obrigação de uma escola cidadã e preparada para qualquer tipo de aluno.

Além da Constituição Federal do Brasil, lei máxima do País, outras inúmeras leis, Decretos e Recomendações são utilizados para amparar a inclusão. Vejamos o que diz a Lei de Diretrizes e Bases (LDB) (BRASIL, 1996) em seus artigos $2^{\circ}$ e $3^{\circ}$, relacionados aos fins da educação:

Art. $2^{\circ}$ A educação, dever da família e do Estado, inspirada nos princípios de liberdade e nos ideais de solidariedade humana, tem por finalidade o pleno desenvolvimento do educando, seu preparo para o exercício da cidadania e sua qualificação para o trabalho.

Art. $3^{\circ} \mathrm{O}$ ensino será ministrado com base nos seguintes princípios: Iigualdade de condições para o acesso e permanência na escola.

Ademais, encontramos escolas que desejam ser inclusiva, cumprir orientações dadas pela educação especial atual, no entanto enfrentam situações que não podem ser resolvidas no próprio ambiente escolar. Diante desse cenário, como deve ser uma escola que deseja ser inclusiva? Quais os limites e possibilidades? Existem diferenças entre tipos de escolas que podem e as que não podem ser inclusivas? Pré-requisitos para continuidade de estudos pode afetar a inclusão? Que escola pode ser chamada escola inclusiva?

É notório que existem diferenças entre uma escola que deseja e a que não quer ser inclusiva. Estas diferenças devem ser levadas em consideração a partir do nível ou da modalidade de educação oferecida. Por exemplo, fazer inclusão em escolas básicas, 
em escolas que recebem alunos com a mesma faixa etária acredita-se ser possível e real, fazer inclusão em escolas profissionais que exigem escolaridade e que os alunos possuem as mais variadas idades é real, mas nem sempre é factível e possível. Se a escola regular profissional optar por uma posição radical e entender que só poderá trabalhar por meio da inclusão, muitos alunos com deficiência continuarão sem estudar e sem receber qualificação escolar necessária para inclusão no mundo do trabalho.

Isso foi ratificado pelos alunos quando questionados sobre o tipo de escola que preferem estudar, ao contrário ao que se tinha pensado, a maioria, quase sessenta por cento prefere estudar em turmas em que seus colegas também possuem algum tipo de deficiência, aproximadamente vinte e cinco por cento prefere estudar com os dois tipos de alunos, ou seja, em escolas que possuem alunos com e sem deficiência e, menos de vinte por cento dos alunos com deficiência pesquisados, preferem estudar em uma escola que não possui alunos com deficiência.

No Brasil é expressivo o percentual de pessoas com deficiência que não possuem escolaridade e são analfabetas. Isso faz com que não possam ser incluídas nos primeiros anos escolares em uma escola regular, pois normalmente possuem idade superior e, como adultos, estão fora do perfil exigido para ingressar na escola básica. Pelo censo de 2010 (BRASIL, 2012), mais de sessenta por cento das pessoas com deficiência não terminaram o primeiro grau e, consequentemente, são também excluídos de outras modalidades de ensino, como: a educação profissional, o ensino médio e o ensino superior, pois sem a educação básica não é possível continuar a trajetória escolar.

Assim, normalmente as pessoas com deficiência e analfabetas não são incluídas em classes regulares de ensino formal destinado aos primeiros anos escolares e passam a procurar alternativas para ingressar no mercado de trabalho. A escola profissional passa a ser uma dessas alternativas, mas essa escola também encontra dificuldades em incluir a pessoa com deficiência junto aos demais alunos sem deficiência, pois as habilidades construídas no decorrer da escolarização ou da própria vida nem sempre estão no mesmo nível, apesar de pessoas com deficiência e sem deficiência possuírem a mesma idade.

Sem conhecimentos prévios, sem alfabetização, uma tentativa de inclusão que não leve em consideração a educação básica ou anterior pode se tornar frustrante para o próprio deficiente que tenderá a não adaptar-se ao processo e sentir-se-á com dificuldades de acompanhar uma turma com tantas diferenças que vão além da sensorial, visual ou física. Vale citar aqui um trecho da redação do autor Walter 
Williams que escreveu nas páginas amarelas da Revista Veja de 9 de março de 2011, quando sua reflexão é aplicável para pessoas com deficiência que possuem muitas dificuldades em relação aos demais integrantes de uma escola regular:

Se você está aprendendo a lutar boxe e sua primeira luta é contra Mike Tyson, você está liquidado. Você pode ter excelente potencial para ser boxeador, mas não dá prá começar contra Tyson. As ações afirmativas, neste sentido, são cruéis, reforçam os piores estereótipos raciais e mentais (WILLIAMS, 2011).

Isso significa que um aluno com algum tipo de deficiência e que também é analfabeto poderá enfrentar dificuldades em ser incluído em uma escola regular. Aquele que é analfabeto e adulto, normalmente fica fora da escola regular pública que responde pela alfabetização e, também ficará fora da escola profissional que exige certo nível de escolaridade para o ingresso em seus cursos. O EJA (Educação de Jovens e Adultos) oferece cursos, normalmente de alfabetização adulta, mas tais cursos nem sempre estão preparados para receber a diversidade da falta de escolaridade, a diversificação das idades e dos tipos de deficiência, quando serão reunidos em uma mesma sala de aula.

É para esses alunos excluídos da escola formal, que lhes dar como única opção a inclusão é também excluí-los. A inclusão no sentido radical ${ }^{5}$ é utopia. A realidade nos mostra que antes de incluí-los na educação profissional, ou em um curso que lhe proporcionará uma competência para o mercado de trabalho, esses alunos necessitam receber formação básica para prosseguir em seus estudos ou mesmo competências mínimas exigidas no perfil do trabalhador e, talvez esse seja o grande quesito que os fazem preferir estudar em escolas especiais.

Estamos aqui tratando da escola inclusiva seus limites e possibilidades, visto que a pesquisa aconteceu junto às escolas profissionais, faz-se necessário, abrir um parêntese para apresentar resumidamente a origem da escola profissional para pessoas com deficiência, seja ela inclusiva ou não.

Ao tratar da escola profissional inclusiva, traz-se à tona o registro das primeiras escolas profissionais do Brasil destinadas às pessoas com deficiência. Em 1931, se deu o início da educação profissional para as pessoas com deficiência. Foi quando surgiram

\footnotetext{
${ }^{5}$ Inclusão no sentido radical, neste caso, se refere a escolas que defendem que a pessoa com deficiência $(\mathrm{PcD})$ tendo ou não o pré-requisito necessário para acompanhar determinada turma de alunos que não possuem nenhum tipo de deficiência, devem estar incluídos nestas turmas, independente do resultado ou da exclusão natural que poderão sofrer não apenas pela deficiência, mas especialmente, pela falta de conhecimentos prévios e necessários para avançar na aprendizagem escolar.
} 
escolas para esse fim. Não eram escolas consideradas inclusivas, mas eram fundamentais para aquele aluno que não tinha a trajetória escolar necessária para ingressar na escola regular e enfrentar os desafios do mundo escolar.

Ainda naquele ano, o Instituto Nacional de Surdos da cidade do Rio de Janeiro consolidou o seu caráter de estabelecimento profissionalizante, com a criação de oficinas de costura e bordado para as pessoas com deficiência do sexo feminino, bem como o IBC, destinados às pessoas com DV, que passam a se engajar no ensino profissionalizante, como alternativa para aprendizagem de uma profissão, como vemos na citação abaixo:

Em ambos os Institutos, algum tempo depois da inauguração, foram instaladas oficinas para a aprendizagem de ofícios. Oficinas de tipografia e encadernação para os meninos cegos e de tricô para as meninas; oficinas de sapataria, encadernação, pautação e douração para os meninos surdos (MAZZOTA, 1996, p.29).

Em 1951, foi criado o primeiro curso normal para professores na área da surdez. O Instituto Nacional de Surdos recebeu a visita de Hellen Keller - filosofa já referenciada na linha do tempo das pessoas com deficiência, no item anterior.

Em 1954, nasceu a reabilitação no Brasil, ou seja, a necessidade da criação de centros com aparelhos e instrumentos necessários para fazer a reabilitação ou o tratamento da Pessoa com Deficiência - PcD. Assim, inaugurou-se um dos primeiros centros de reabilitação que foi a Associação Brasileira Beneficente de Reabilitação (ABBR), a qual até hoje conta com apoio de grandes empresários e forma fisioterapeutas e terapeutas ocupacionais.

Diferentemente dos Institutos retrocitados, que atendiam apenas a pessoas com alguma deficiência, o SENAI $^{6}$ foi criado em 1942 para atender a qualquer tipo de cidadão, fosse ele com deficiência ou não, preparando o indivíduo para o mercado de trabalho formal. Dessa forma, atendia prioritariamente a alunos sem deficiência, sem deixar de propor atendimento para as pessoas com deficiência.

Nesse contexto, as escolas do SENAI atendiam a pessoas com deficiência, mas, não havendo uma obrigação legal, isso era realizado na medida em que os representantes das escolas desejassem, ou que algum empresário se sensibilizasse e fizesse a solicitação para atendimento de alunos que tivessem algum tipo de deficiência.

\footnotetext{
${ }^{6}$ Serviço nacional de Aprendizagem Industrial, parte do Sistema "S" que realiza educação profissional para todo e qualquer cidadão.
} 
Era muito comum a capacitação de pessoas cegas ou deficientes visuais que, após serem treinadas, podiam prestar trabalhos nas linhas de produção industrial em que, normalmente, se possibilitava empregados para exercer funções repetitivas. Esses empregados não podiam e nem deviam ser levados a pensar, muito menos ingressar em postos de trabalhos de chefias com direito ao poder de decisão. Esses empregados com deficiência eram contratados muitas vezes em resposta a sentimentos de assistencialismo e de piedade empresarial.

Nos tempos de hoje, no entanto, a escola profissional é preconizada como uma escola que necessita ser inclusiva e que se prepara para atender a uma indústria inclusiva, fato que pode ser considerado como utopia em alguns momentos, mas em outros, como uma necessidade e um dever, visto necessitarem apoiar os empresários a cumprir a lei (BRASIL, 1991) que obriga a toda a empresa com mais de cem empregados a contratar pessoas com deficiência em seus quadros de empregados.

Pode-se descrever inúmeros conceitos que nos levariam a reconhecer a escola inclusiva, mas um conceito geral que reúne todos os elementos de uma definição pode ser revelado 'como uma escola que está preparada para atuar na diversidade, receber qualquer aluno ou aluna, seja ele uma pessoa com ou sem deficiência'. Como lembra Matarazzo (2009, p.119), “[...] é importante lembrar que, quando falamos em melhorias e em 'escola inclusiva', estamos falando de um espaço melhor para todos". A autora ainda explica o que seja esta escola inclusiva e preparada para atender às pessoas diferentes:

Para se ter uma ideia melhor do que seria ideal para ter uma escola realmente inclusiva, é preciso levar em conta não apenas o que ela oferece em termos de espaço e acessibilidade, mas também o preparo de seus professores para atender a alunos com todos os tipos de necessidades (MATARAZZO, 2009, p.120).

Muitas escolas dizem-se inclusivas, mas não possuem estruturas ou acessibilidades políticas, pedagógicas, metodológicas, físicas e outras, necessárias para atender alunos levando em consideração suas diferenças. A escola inclusiva é uma necessidade legal, mas para que ela se torne realidade, ela deve pensar diferente para atender as diferenças. Para que a realidade da inclusão se efetive e ultrapasse a utopia, lançaram-se cinco questões para pessoas com deficiência que se encontram na educação profissional, seja em turmas incluídas, seja em turmas especiais, formadas somente por alunos com algum tipo de deficiência. 
Quando questionados sobre a extinção das escolas especiais, entre elas: o INES (Instituto Nacional de Educação dos Surdos); o IBC (Instituto Benjamin Constant) APAES (Associação de Pais e Amigos dos Excepcionais), APADA (Associação dos Pais e Amigos dos Deficientes Auditivos); a FENEIS (Federação Nacional de Educação e Integração dos Surdos), entre outras; a resposta para tal questão, foi ainda mais surpreendente, apresentou um resultado quase que unanime e apenas um dos pesquisados foi favorável a extinção das escolas especiais e que todos os alunos com ou sem deficiência deveriam estar na escola regular. Isso foi surpreendente na pesquisa, não se esperava este contingente de respostas favoráveis às escolas especiais. Entre as principais justificativas por tão alto percentual de escolha de não extinção das escolas especiais, selecionamos as seguintes falas dos alunos com deficiência pesquisados:

Primeiro registro: [...] existem deficientes que não se adaptam nas demais escolas e precisam de acompanhamento específico. (Aluno 3AL). Segundo registro: Existem pessoas diferentes com necessidades diferentes. (aluno 4- AL); Terceiro registro: É fundamental a existência dessas escolas, pois tem estrutura direcionada aos alunos com deficiência. (Aluno 1- BA)Quarto registro: Porque é o meio deles saírem dessas escolas e, mais tarde poderão ingressar em uma escola regular normal. (Aluno 2 - BA).Quinto registro: Escolas precisa, importante responsável, futuro pessoas alunos, traduzido como: Essas escolas especiais, são necessárias e são importantes para preparar os alunos com deficiência para seu futuro. (aluna 1- GO).Sexto registro: Pode ser o lugar certo para muitas pessoas com deficiência poderem estudar. (Aluno $1 \mathrm{CE}$ ).Sétimo registro: Já são poucas escolas para deficientes, imagina se acabarem? (aluno 3-CE).Oitavo registro: É necessário que existam essas escolas especiais, não apenas para pessoas com deficiência, mas para quem quiser estudar nelas (Aluno 1 - DF).Nono registro: [...] são escolas que acolhem os alunos com deficiência, quando os pais tem medo de colocar os filhos em escolas regulares, porque as escolas não orientam. (aluno 1- MA).Décimo registro: A inclusão exige escola bilíngue. (aluna 1 - GO).Décimo primeiro registro: Os alunos tem direito de escolher. Essas escolas lutam mais pelos direitos das pessoas com deficiência. (Aluno 3PB).Décimo segundo registro: No início os deficientes precisam conviver com os outros deficientes. (aluno 2- PB).Décimo terceiro registro: Essas escolas tem a sua própria cultura surda. (aluna 1RJ).Décimo quarto registro: porque a extinção destrói a história da pessoa com deficiência. (Aluna 3- RJ).Décimo quinto registro: $\mathrm{Na}$ minha opinião as crianças deficientes do mundo precisam ser alfabetizadas para depois de juntar com as pessoas não deficientes, onde o papel dessa escola normal era de também fazer isso, mas querem extinguir quem faz. (aluno 1- RN).Décimo sexto registro: É fundamental a existência dessas escolas por terem estruturas condicionadas e direcionadas aos alunos (Aluno 3- RN).Décimo sétimo registro: Uma instituição como essa é uma boa forma de ajudar as pessoas com deficiência. (Aluno $2-\mathrm{RS}$ ).Décimo oitavo registro: $\mathrm{O}$ 
trabalho deve existir, pois é diferente. (aluno 1-SC).Décimo nono registro: Passamos por um processo lento e gradual de adaptação e transição daquela fase de integração para a inclusão prática e factível. (Aluno 1-SP).Vigésimo registro: O não funcionamento dessas escolas prejudica o ensino que para mim contribui muito para a educação das pessoas especiais. (Aluno 2- SP).

Os registros acima citados pelos alunos com deficiência pesquisados, ratificam a necessidade de existirem escolas especiais, seja para atendimento daquele aluno que ainda não quer ir para a escola regular, seja para aquele aluno que necessita de prérequisitos para a inclusão em escola de ensino para alunos sem deficiência.

Daí a necessidade das escolas de qualquer nível escolar, mesmo que escolas tidas como 'regulares', mas que desejam ser inclusivas reverem seus projetos pedagógicos e sua sistemática de avaliação, procurando flexibilizar o currículo e ampliar as condições de acesso das pessoas com deficiência em seus cursos, especialmente, levando em consideração a legislação e as possibilidades que esta apresenta quando se capacita e avalia pessoas com deficiências. Será necessário que as escolas se preparem para receber este tipo de aluno e não que este aluno tenha que se adaptar ao que a escola oferece e, que nem sempre atende as suas necessidades específicas da sua deficiência.

Uma entrevista realizada com o autor Boaventura de Souza Santos, a qual foi realizada por Imaculada Lopez, da redação Sem Fronteiras no ano de 2001, encontramos alguns pontos relevantes que fortalecem a ideia que se tem defendido no presente texto, ou seja, que precisamos tratar diferente a diferença.

O universalismo que queremos hoje é aquele que tenha como ponto
em comum a dignidade humana. A partir daí, surgem muitas
diferenças que devem ser respeitadas. Temos direito de ser iguais
quando a diferença não inferioriza e direito de ser diferentes
quando a igualdade nos descaracteriza.O princípio da igualdade nos
obriga a políticas de redistribuição de riquezas. Mas, ao mesmo
tempo, o princípio da diferença nos obriga a ter políticas de
reconhecimento e aceitação do outro. É complicado, pois precisa ser
um processo paralelo. Não podemos reconhecer a identidade dos
indígenas e, ao mesmo tempo, tirar suas terras e riquezas naturais.
Portanto, a sociedade civil transnacional ainda é um grande projeto em
construção. (SANTOS, 2010, grifo nosso).

Quando a diferença nos inferioriza é necessário que a mesma seja tratada de forma diferente. Para isso, surgem soluções que só poderão acontecer desde que a 
escola entenda a razão de 'separar para incluir' e que atenda as pessoas com deficiência, levando em consideração, além do tipo de deficiência, as suas necessidades educacionais especiais que trabalham também os pré-requisitos necessários para ingresso em turma regular, especialmente conhecimentos técnicos e de nível básico de escolaridade.

Acredita-se que, com a nova legislação e com o ingresso da pessoa com deficiência desde a mais tenra idade nas classes regulares e já nos primeiros anos escolares, se dará a esse público, condições de prosseguir seus estudos incluídos, mas isso não acontece como uma poção mágica que funciona a todos igualmente. Isso deverá acontecer de forma gradativa e como um processo natural. Atualmente, dizer que a escola só poderá atender alunos com deficiência em turmas regulares, ou seja, em escolas que se dizem totalmente inclusivas, pois entendem que não podem 'separar para incluir', ainda tem aspectos utópicos.

É preciso levar em consideração que nos últimos vinte anos se avançou muito em termos de educação para pessoas com deficiência, isso é positivo, mas o quadro atual ainda acena para a necessidade de atendimento escolar que não seja apenas inclusivo, ou seja, não é possível que hoje aceitemos apenas, turmas de alunos com deficiência juntos aos alunos sem deficiência mesmo que elas não tenham os pré requisitos necessários.

Para o aluno, que não está alfabetizado, que é um adulto que não conseguiu fazer parte da classe regular, se faz necessário um conjunto de mudanças que ultrapassem o querer pedagógico de fazer educação profissional para pessoas com deficiência apenas de um modo inclusivo, que seja sim 'preferencialmente' inclusivo, assim como preconiza a Lei de Diretrizes e Bases da Educação, Capítulo $5^{\circ}$ da educação especial, art. 58 que diz: "Entende-se por educação especial, para efeito dessa Lei, a modalidade de educação escolar, oferecida, preferencialmente, na rede regular de ensino, para educandos portadores de necessidades especiais.” (BRASIL, 1996), mas jamais 'unicamente' inclusivo.

O Plano Nacional de Educação (PNE), em seu texto, trás essa ideia do 'preferencialmente' enfatizando o resultado de uma conquista árdua que se deu na luta dos representantes das organizações não governamentais que atendem as pessoas com deficiência durante a tramitação no Senado Federal que aprovou o texto do PNE contendo a palavra 'preferencialmente'. Aparentemente, foi um ganho parcial para estas instituições que lutaram, mas agora o Plano Nacional de Educação tramita na Câmara 
dos Deputados e, novamente, as instituições não governamentais que atendem as pessoas com deficiência, iniciam uma luta para resgatar o apoio financeiro do Governo Federal.

\section{Considerações Finais}

A solução, diante das dificuldades em incluir alunos com deficiência em turmas regulares da educação profissional, pode estar em organizar turmas fechadas, ou separadas, que passam a ter alunos com características, tipos de deficiências e nível de escolaridades semelhantes. Turmas em que todas as pessoas possuem algum tipo de deficiência, seja legal ou não, assim como pessoas que possuem outras necessidades relacionadas aos pré-requisitos para avançar na formação/capacitação profissional.

Essa é uma alternativa que se deveria levar em consideração e receber apoio de órgãos educacionais que, muitas vezes, criticam esses tipos de turmas apenas por não estarem incluindo todos os alunos com deficiência em classes regulares, ou são escolas criticadas pelo simples fato de colocar pessoas com o mesmo perfil e com um mesmo tipo de deficiência em um mesmo espaço educacional. As criticas incluem frases como: 'esta escola é excludente'; 'esta escola não faz inclusão e não respeita as diferenças'; 'esta escola segrega' e, ainda: 'esta escola separa', quem critica esquece de que tal escola, muitas vezes, separa para incluir. As experiências de turmas fechadas ${ }^{7}$ tem sido a solução alternativa para muitos excluídos que precisam da formação que antecede qualquer nível de ensino.

Isso pode não ser a visão idealista, pois seria imprescindível que todas as pessoas com deficiência tivessem acesso ao ensino básico, concluíssem este ciclo e tivessem a preparação necessária para enfrentar os próximos níveis que a escola oferece. Antes disso, em muitos momentos, separar para incluir, ou seja, oferecer um ensino de acordo com o nível individual, caminhando em prol de que, esse indivíduo com deficiência, se aproxime do nível de aprendizagem de determinada turma regular pode ser, o que se pode fazer de real, no momento atual.

Acredita-se que este tipo de ensino (inclusivo) só será totalmente viável, após os resultados positivos e efetivos dos estudantes incluídos nas escolas da rede pública e

\footnotetext{
${ }^{7}$ Neste texto, esse tipo de turma significa: turmas de alunos que são formadas a partir de alguma semelhança relacionada a deficiência, ou seja, uma turma de alunos em que todos possuem alguma deficiência, seja física, visual, auditiva ou intelectual.
} 
privada que também atendem outros tipos de alunos sem deficiência. Assim, esse aluno com deficiência chegará ao ensino médio ou profissional pelas vias da educação regular, isso, atualmente, não é uma regra geral e, muitos alunos, ainda são excluídos do avanço escolar, ou mesmo na escola básica.

Dessa forma, com o passar dos anos, quando todo aluno com deficiência ingressar na educação inicial, especialmente na primeira série da educação básica, na alfabetização regular, a sequencia lógica da continuidade de estudos em classes inclusivas será algo real e possível, mas hoje não é essa a nossa realidade. Hoje precisamos pensar naqueles que não ingressaram desde a mais tenra idade nas classes regulares e que são pessoas que precisam de atendimento educacional diferenciado.

Parafraseando o Sr. Luiz Alberto Silva (apud PORTAL DO APRENDIZ, 2005), que na época era presidente da Federação Nacional das APAES, dependendo do tipo de deficiência, a inclusão muitas vezes pode ser prejudicial para a criança. Para ele, num sentido mais amplo da palavra inclusão, é possível dizer também que um aluno com deficiência que esteja matriculado numa escola especial, ou mesmo em uma turma de alunos formada por aqueles que possuem alguma deficiência, também pode ser visto como incluído na sociedade.

Se essas crianças forem para uma escola ruim e despreparada, certamente ficarão excluídas da sociedade porque não terão seus limites respeitados e não conseguirão acompanhar a turma. A escola especial vai continuar existindo porque ela ajuda a incluir a pessoa na sociedade. (PORTAL DO APRENDIZ, 2005).

E para aqueles que consideram que as APAEs - Associação de Pais e Amigos dos Excepcionais ou que as escolas especiais, na maioria ONGs- Organizações Não Governamentais, não educam, precisam conhecer de perto o trabalho que muitas destas realizam no Brasil, não apenas buscando conhecer cada especificidade de seus alunos, como trabalhando a inclusão e as diferenças. Claro que se sabe que muitas ONGs necessitam de atualização urgente, mas precisa-se considerar que muitas das nossas escolas regulares também estão defasadas e também não se pode afirmar que seria o melhor local para receber a pessoa com deficiência.

A sugestão seria que uma escola complementasse a outra, ou seja, que as escolas especializadas pudessem ensinar o que de melhor sabem fazer no atendimento especializado às pessoas com deficiência e, que a escola regular, oferecesse a qualidade 
do ensino que tanto almejamos. A troca entre os dois tipos de escola, a complementação entre saberes e experiências seria um aprendizado a todas as instituições do Brasil que atuam com pessoas com deficiência, sejam elas formais ou não formais.

Ressalta-se ainda, o resultado da terceira Conferencia Nacional dos Direitos das Pessoas com Deficiência, a qual foi realizada nos dias 03 a 06 de dezembro de 2012, na cidade de Brasília, a qual reuniu Delegados de todos os estados do Brasil, o desejo dos representantes pela continuidade das escolas especiais. Isso ficou registrado na Moção de Aplauso, numero três, destinada a Presidência da República, que foi redigida pelas Instituições presentes ${ }^{8}$ :

Nós, delegados da III Conferência Nacional dos Direitos da Pessoa com Deficiência, representantes dos Estados Brasileiros, manifestamos o nosso aplauso às falas da Exma. Presidenta da República, Sra. Dilma Rousseff, da Exma. Ministra Chefe da Casa Civil, Sra. Gleice Hoffman e da Ministra Chefe da Secretaria de Direitos Humanos, Sra. Maria do Rosário Nunes, que ao se pronunciarem destacaram a oferta das escolas especiais como modalidade de ensino. Ainda na fala na Presidenta Dilma, foi ressaltada e reconhecida à importância do trabalho que as Instituições Filantrópicas e as Escolas Especiais iniciaram e continuam desempenhando com grande relevância dentro do país. Concordamos com a fala da Presidenta de que as Instituições, as Escolas Especiais e as Escolas Inclusivas podem e devem coexistir harmoniosamente. No sentido de reafirmar a regularidade do Governo em oferecer diferentes modalidades, citamos o decreto 7.611/2011, Art $8^{\circ} \S 2^{\circ}$, que além da Escola Especial garante a escola bilíngue para surdos. Reafirmamos o nosso aplauso (BRASIL, 2013).

Diante do texto acima oriundo da Conferencia Nacional dos Direitos da Pessoa com Deficiência e, especialmente, do querer dos alunos e alunas com deficiência pesquisados, querer esse que foi explicitado nas respostas apresentadas, faz-se necessário o respeito às suas diferenças e a garantia das escolas especiais.

O desejo dos alunos pesquisados precisa ser respeitado e uma frase que parece ser muito usada pelo senso comum e que, deve-se levar em consideração é a necessidade de ouvir os maiores interessados que são as próprias pessoas com deficiência, ou seja, não decidir o que interessa a eles sem chamá-los à discussão. Dessa forma: 'nada sobre eles sem a participação deles'.

${ }^{8}$ CEPDE-RJ, FENASP, FENASPAES e outros. 
Não apoiar a inclusão radical na educação profissional pode ser uma saída, ou seja, a formação de escolas especiais, ou mesmo de turmas fechadas ou segregadas, ${ }^{9}$ ou ainda, as designadas como classes especiais, onde todos possuem algum tipo de deficiência, podendo estar em uma escola regular, mas em uma classe especial, quando isso for necessário. Esta garantia está expressa no item 38 relacionado ao eixo 'Educação' e retirado da terceira conferencia nacional: “Garantir o funcionamento de escolas especiais de boa qualidade para os casos de deficiência intelectual, múltipla e para outras deficiências cuja complexidade exigir ambientes específicos, para o desenvolvimento integral e integrado de seus usuários [...]” (BRASIL, 2013).

Essa alternativa pode ser vista como 'separar para incluir'1, ou seja, pode ser a solução do momento em que a massa da população das pessoas com deficiência já ultrapassaram a idade exigida no ingresso em escolas formais e possuem baixa escolaridade.

A organização de turmas de alunos com deficiência em um mesmo espaço, levando em consideração as características e os pré-requisitos necessários para o ensinoaprendizagem, não os excluí das escolas regulares, ou seja, as classes especiais também podem acontecer dentro das escolas regulares. A classe especial ou a educação realizada pelas escolas especiais podem trabalhar os requisitos necessários para o ingresso desse aluno em turmas regulares e, isso, pode contribuir para trazer as classes regulares aqueles alunos que antes não podiam entrar e permaneciam somente em escolas especiais sem perspectivas, ou seja, as escolas ou classes especiais podem trabalhar os pré-requisitos necessários para uma posterior inclusão.

A matrícula de alunos com deficiência em uma escola preparada para recebê-los representa também uma obrigação legal, mas isso se sugere iniciar na educação préescolar. Temos que lembrar que essas pessoas com deficiência foram segregadas por muito tempo e ainda temos uma parcela significativa dessa população oriunda dessa segregação, assim não se justifica colocar um aluno em um curso profissionalizante sem ter os pré-requisitos necessários, fazendo-o, sentir-se, em alguns casos, em um processo de exclusão natural pelas diferenças técnicas e pedagógicas que tem, como eles próprios, alunos e alunas com deficiência, afirmaram na pesquisa que ora se apresenta parte dos resultados.

\footnotetext{
${ }^{9}$ Termos denominados pelo senso comum para indicar uma turma de alunos composta por alunos que possuem algum tipo de deficiência e não os inclui em turmas regulares do ensino formal (neste texto, igual a 'turmas fechadas').
} 
Cabe à escola de nível básico, profissional, médio, superior, que deseja ser inclusiva, aproximar o ideal da realidade e, para isso, essa escola não pode ser a panacéia de todo o processo de segregação que vivemos até hoje e ser vista como aquela que tem obrigação de realizar um ensino inclusivo. Este tipo de ensino, ou seja, a inclusão de fato, se dará normalmente quando essa escola buscar, por meio da realidade, aproximar-se da inclusão e realizá-la, levando em consideração os limites e as possibilidades de cada indivíduo.

Inclusão escolar é algo possível, mas levando em consideração a real condição de realizar-se. Não se pode exigir que toda a escola seja totalmente inclusiva, se nem mesmo os ambientes escolares são acessíveis, os docentes não estão preparados, o material está inacessível, a comunicação não é possível, os alunos não estão preparados e, as atitudes não condizem com os princípios da inclusão. Educar incluindo alunos com deficiência em uma mesma turma de alunos sem deficiência exige muito mais que o querer político, exige ações concretas, caso contrário este ato de educar pode se tornar um ato de exclusão.

Não adianta a escola 'fazer de conta que ensina' e o aluno 'fazer de conta que aprende'. Sabemos que a inclusão só será possível quando pudermos tratar os diferentes levando em consideração as suas diferenças, caso contrário essa inclusão poderá apresentar resultados desastrosos. Assim, sugere-se trabalhar os diferentes levando em consideração as heranças educacionais impostas pela falta de uma educação ao alcance de todos, que afastou as pessoas com deficiência dos ambientes escolares formais.

Pode-se afirmar que, a partir da análise das respostas oriundas dos alunos com deficiência, separar para incluir, no momento, pode ser a prática possível e necessária para quem defende uma educação ao alcance de todos e acredita na verdadeira inclusão educacional e na capacitação real das pessoas com deficiência.

Separar para incluir pode ser a solução do momento para a educação profissional que se utiliza, além da teoria, de uma constante prática que normalmente acontece nos laboratórios de aprendizagem industrial.

Vale ainda lembrar que, além dos resultados junto aos alunos com deficiência, a pesquisadora coletou e analisou respostas de outros dois segmentos: gestores e docentes que atuam com alunos com deficiência, mas aqui neste artigo se priorizou o desejo do sujeito que entendemos como mais importante no processo, ou seja, o próprio aluno com deficiência. Com certeza outros artigos revelarão o que pensam os demais segmentos pesquisados. 
Este artigo revelou o desejo dos alunos quanto à inclusão na educação profissional e, talvez, tais resultados não deveriam ser apenas preconizados na educação profissional, mas em qualquer modalidade de educação; deveriam ainda, servir de análise por parte da comunidade escolar; por todo o governo e, por aqueles que entendem como a única solução educacional, a inclusão de alunos com deficiência em turmas regulares.

Seria muito importante que antes de, arbitrariamente, criar políticas públicas unicamente inclusivistas, toda a sociedade se preocupassem em perguntar às pessoas com deficiência o que elas realmente desejam para a sua educação e, que preferencialmente, as pessoas com deficiência sejam agentes ativos na criação das políticas educacionais que serão utilizadas por elas.

\section{PROFESSIONAL EDUCATION: SEPARATE TO INCLUDE?}

ABSTRACT: In Brazil, the possibilities and limits of inclusion of students with disabilities $(D P)$ in regular classes is a subject that divides opinion. On one side are those who argue that it is possible to include all students in regular rooms, no matter what type of disability. On the other, there are those who argue that, in some cases it is better for the DP study in a class or special school. The proposed reflection pautara on results of an unpublished doctoral research in education that addresses the issue. Students themselves with disabilities shows that do not always feel included in mainstream classes. What will be the output? Special classes may be a necessary solution to include the excluded?

KEYWORDS: Inclusion. Professional. Special classes.

\section{REFERÊNCIAS}

BRASIL. Secretaria de Direitos Humanos da Presidência da República. Terceira Conferencia Nacional das pessoas com Deficiências: Relatório Final. Brasília, 2013. Disponível em:

<http://www.pessoacomdeficiencia.gov.br/app/sites/default/files/publicacoes/livrorelatorio-3a-conferencia-final_0.pdf>. Acesso em: 21 fev. 2015.

Cartilha do CENSO 2010: Pessoas com deficiência. Brasília, DF: SDH, 2012. 
Ministério da Educação. Lei no 9.394, de 20 de dezembro de 1996. Lei de

Diretrizes e Bases da Educação. Brasília, 1996. Disponível em:

<http://www.planalto.gov.br/ccivil_03/leis/19394.htm>. Acesso em: 25 fev. 2015.

Lei no 8.213, de 24 de julho de 1991. Dispõe sobre os Planos de Benefícios da

Previdência Social e dá outras providências. Disponível em:

<http://www.planalto.gov.br/ccivil_03/leis/18213cons.htm>. Acesso em: 28 jan. 2015.

INSTITUTO BRASILEIRO DE GEOGRAFIA E ESTATÍSTICA [IBGE]. Censo 2010. 2010. Disponível em:

<http://www.faders.rs.gov.br/portal/index.php?id=noticias\&cod=2128>. Acesso em: 16 jan. 2015.

MATARAZZO, C. Vai encarar?: A nação (quase) invisível de pessoas com deficiência. São Paulo: Melhoramentos, 2009.

MAZZOTA, M. J. S. Educação especial no Brasil: história e políticas Públicas. São Paulo: Cortez, 1996.

PORTAL DO APRENDIZ. Limite de integração de alunos deficientes divide especialistas. mar. 2005. Disponível

<http://aprendiz.uol.com.br/content/jiwrujiuet.mmp>. Acesso em: 25 jan. 2015.

SANTOS, B. de S. Em busca da cidadania global. Entrevistador: Immaculada Lopez.

Revista ACERGS, Porto Alegre, n.9, jun. 2010. Disponível em:

<http://pwweb2.procempa.com.br/pmpa/prefpoa/acergs/usu_doc/read_9_ii.txt > Acesso em: 25 jan. 2015.

WILLIAMS, W. O mercado Vence o Racismo. Veja, São Paulo, n.2207, 9 mar. 2011. 